\title{
FATORES VISUAIS DE DESIGN E SUA INFLUÊNCIA NOS VALORES DE COMPRA DO CONSUMIDOR
}

THE INFLUENCE OF PERCEIVED DESIGN CHARACTERISTICS ON CUSTOMERS' PURCHASE VALUES

RESUMO

Este artigo explora o tema das experiências dos consumidores nos ambientes físicos oferecidos pelas empresas de serviços, avaliando o impacto de fatores visuais de design sobre a percepção de valor por parte dos clientes de um ponto de venda com autosserviço. Foram identificados os valores de compra dos usuários e as características de design percebidas no âmbito do varejo de autosserviço, envolvendo leiaute, sinalização e iluminação presentes no ambiente. $\mathrm{O}$ valor de compra, considerado uma resposta interna do consumidor ao ambiente de varejo, incluiu dimensões utilitárias e hedônicas. O método aplicado foi o cross-sectional survey, com a aplicação de questionário a 274 estudantes universitários, os quais manifestaram sua percepção de três diferentes livrarias com autoatendimento, ilustradas por fotos. Os resultados obtidos apontaram quatro características de design com influência significativa na formação de valor de compra dos consumidores sob a perspectiva utilitária e hedônica.

\section{Cláudio Hoffmann Sampaio}

Professor da Faculdade de Administração, Contabilidade e Economia, Pontifícia Universidade Católica do Rio Grande do Sul - RS, Brasil csampaio@pucrs.br

\section{Gianpietro Sanzi}

Professor do Instituto de Pós-Graduação de Goiânia - G0, Brasil

gsanzi@terra.com.br

\section{Luiz Antonio Slongo}

Professor do Centro de Estudos e Pesquisa em Administração, Universidade Federal do Rio Grande do Sul - RS, Brasil laslongo@ea.ufrgs.br

\section{Marcelo Gattermann Perin}

Professor da Faculdade de Administração, Contabilidade e Economia, Pontifícia Universidade Católica do Rio Grande do Sul - RS, Brasil mperin@pucrs.br

Recebido em 16.04.2008. Aprovado em 18.08.2009

Avaliado pelo sistema double blind review

Editora Científica: Suzane Strehlau

\begin{abstract}
This paper explores the theme of consumer experience in the physical environment offered by service companies. The research evaluated the influence of design characteristics on the perception of value by customers of self-service retail purchases. We identified the consumer purchase values and the design characteristics perceived in the context of self-service retail, regarding lay-out, signage and illumination in the environment. The applied method was a cross-sectional survey, with a sample of 274 undergraduate students, who manifested their perceptions of three different self-service bookstores, illustrated with photos. The results pointed out to four design characteristics with significant influence on the formation of value of the consumer's purchase from both the functional and hedonic perspectives.
\end{abstract}

PALAVRAS-CHAVE Características de design, valores de compra do consumidor, valor hedônico, valor utilitário, livraria KEYWORDS Design characteristics, consumer purchase values, hedonic value, utilitarian value, bookstore. 


\section{INTRODUÇÃO}

O impacto da atmosfera, do design físico ou de elementos decorativos no comportamento de clientes e funcionários, é reconhecido na práxis gerencial e mencionado em quase todos os textos de marketing para o varejo e comportamento organizacional (BITNER, 1992). Kotler (1973) foi um dos primeiros autores a chamar a atenção para este tema, o qual, a despeito da quantidade e da qualidade das pesquisas desenvolvidas ao longo das últimas décadas, segue tendo destaque acadêmico e gerencial no ambiente de marketing. $\mathrm{O}$ interesse crescente por esse assunto é ratificado por estudos recentes a ele dedicados. Muitos desses trabalhos têm como ponto de partida o framework criado por Russell e Mehrabian (1976), pesquisadores de Psicologia Ambiental, e como referência o estudo de Bitner (1992) sobre os "cenários de serviços" (GATTO, 2002; ZORRILLA, 2002; LIBERALI e outros, 2003; CARVALHO e MOTTA, 2002).

Apesar de todos os estudos que se seguem ao longo do tempo, segundo Carvalho e Motta (2002), os efeitos reais do ambiente ainda continuam pouco explorados e inadequadamente conceituados, e suas implicações nos comportamentos de compra carecem de documentação científica, mesmo quando são consideradas somente as instalações físicas dos cenários. Esses autores defendem que os estudos sobre os espaços de serviços precisam de mais proposições de instrumentalização teórica.

A relevância desses estudos também encontra justificativa nas constatações de Zorrilla (2002), que alertam para a eficiência decrescente das fórmulas do marketing tradicional no varejo (produto, preço, promoção e praça), estimulando os empresários do setor a se esforçarem para conquistar o consumidor buscando novas ideias para reter e tornar fieis os clientes que demandam mais valor para seu dinheiro e seu tempo. O ambiente comercial, portanto, vem se destacando como um componente estratégico que permite diferenciar e posicionar as marcas dos varejistas, além de proporcionar uma experiência que venha a reforçar as percepções sobre o produto a adquirir ou sobre a qualidade do serviço prestado (ZORRILLA, 2002).

Nesse sentido, este artigo apresenta os detalhes de um estudo que objetivou ampliar a compreensão sobre as experiências dos consumidores nesses ambientes, por meio da avaliação do impacto de fatores visuais de design sobre a percepção de valor por parte dos clientes de um ponto de venda com autosserviço. Ademais, o artigo explora a discussão dos resultados de uma etapa qualitativa preliminar, desenvolvida para identificar os principais fatores visuais de design de lojas de varejo de autosserviço, bem como valores utilitários/funcionais e hedônicos na percepção dos clientes desse setor. Os resultados encontrados foram a base para a análise e discussão de implicações acadêmicas e gerenciais, contribuindo para a ampliação dos trabalhos que abordam o tema.

\section{REFERENCIAL TEÓRICO}

Em um sentido amplo, a experiência proporcionada aos consumidores de serviços vem sendo considerada uma ferramenta estratégica colocada a serviço da vantagem competitiva nas empresas. Pine II e Gilmore (1998) sustentam que, depois das commodities, bens e serviços, a experiência pode ser definida como a quarta oferta econômica. Esses autores defendem que, enquanto as commodities se gastam com o uso, os bens são tangíveis e os serviços intangíveis, as experiências são memoráveis, existem internamente na mente de um indivíduo que as vivenciou, seja emocional, física, intelectual, ou mesmo espiritualmente.

Zorrilla (2002), por sua vez, argumenta que para os consumidores mais exigentes o varejo de experiência é a oportunidade emergente. Segundo Gatto (2002), pesquisas têm ratificado essa disposição ao demonstrarem que a dimensão lúdica do shopping tem se tornado mais decisiva na formação dos modelos de comportamento do consumidor. Ao incorporar elementos sensoriais à experiência, esta é capaz de atrair e reter os consumidores na busca crescente de vivências de compra entusiasmantes e envolventes (GATTO, 2002).

Nesse sentido, além da importância da funcionalidade do ambiente da loja para os clientes, foram desenvolvidos estudos relacionando estímulos e evidências físicas do ambiente de varejo e sua influência sobre os estados emocionais dos clientes e sobre as experiências de consumo.

Uma das primeiras propostas de criação de um modelo conceitual da influência do ambiente nas respostas emocionais dos clientes foi apresentada por Russell e Mehrabian, (1976). Esses autores, psicólogos ambientais, reconheceram que estímulos físicos, presentes em um determinado ambiente, conjuntamente com a personalidade dos consumidores, influenciam diretamente estados emocionais de um indivíduo e, por consequência, seu comportamento. Estudos posteriores, como o de Bitner (1992), Sherman e outros (1997), Baker e outros (2002), Gatto (2002) e Zorrilla (2002), aprofundaram essas questões trazendo o conceito de "cenários de serviços".

No modelo apresentado por Bitner (1992), o cenário de serviços possui quatro dimensões ambientais que interferem na qualidade percebida do serviço. São elas: condições 
ambientais; espaço-função; sinais, símbolos e objetos; e social. As respostas dos indivíduos a cenários encontram seu fundamento na psicologia ambiental, que pode ser resumida no seguinte modelo simplificado: as características físicas dos ambientes influenciam algum estado interno do consumidor, que, por sua vez, influencia o seu comportamento dentro do cenário. Funcionários e clientes reagem às dimensões físicas do seu entorno físico de modo cognitivo, emocional e psicológico, de maneira claramente interdependente (ZEITHAML e BITNER, 2003).

Numa linha similar, mas buscando mais especificamente o entendimento da relação entre evidências físicas e os estados emocionais dos consumidores, Sherman e outros (1997) avaliaram fatores de design para medir os efeitos do ambiente de pontos de venda nas emoções do consumidor e no seu comportamento. Os fatores de design desses autores denotaram características do ambiente como: organização, dimensão dos espaços de circulação, limpeza e exposição das mercadorias.

Baker e outros (2002) trataram da percepção do cliente de varejo em relação à qualidade, preço e valor e, para tanto, expandiram o modelo conceitual de Sherman e outros (1997), incluindo além dos fatores de design, os fatores sociais e ambientais. Os fatores sociais referem-se a interações entre funcionários e clientes e clientes entre si. Os fatores ambientais envolvem temperatura, cheiros e sons, percebidos no subconsciente dos consumidores. Os fatores de design seguem a linha de Sherman e outros (1997) e dizem respeito a aspectos mais visuais e conscientes, se comparados aos fatores ambientais.

Diferentemente dos estudos anteriormente discutidos de Bitner (1992), Sherman e outros (1997) e Baker (2002), Gatto (2002) traz uma abordagem mais ampla do ambiente de varejo, relacionando-o como um aspecto de reforço dos vínculos com o cliente. A autora apresenta o conceito de atmosfera do ponto de venda e agrupa os fatores que caracterizam esta "atmosfera" em: táteis (referentes aos materiais utilizados, à temperatura e à qualidade do ar); sonoros (os apreendidos pela música ambiente e ruídos do ponto de venda); olfativos (emanados por aromas artificiais ou naturais); visuais (percebidos por meio das cores, dos materiais, da arquitetura interna e do merchandising); sociais (propiciados pelo contato entre clientes e funcionários e pela densidade de clientes); e gustativos (providos pela degustação dos alimentos). A atmosfera do ponto de venda é uma variável de marketing a ser gerenciada estrategicamente por ser um importante instrumento de diferenciação do varejo e do posicionamento da marca (GATTO, 2002).
Num entendimento bastante similar ao de Gatto (2002) no que se refere à utilização do ambiente na experiência de compra e no reforço e posicionamento de marca, mas partindo das dimensões de Bitner (1992), o modelo conceitual proposto por Zorrilla (2002) divide o chamado ambiente global de um ponto de venda em quatro dimensões assim denominadas: exterior; condições ambientais; interior; e social. Segundo essa autora, o ambiente global pode influir favoravelmente na experiência de compra, na percepção da mercadoria, no serviço e na imagem e posicionamento do estabelecimento. Em decorrência, essa influência pode fortificar os vínculos de fidelidade e de satisfação, prolongando a permanência do consumidor no estabelecimento e podendo trazer maior rentabilidade ao varejista. Zorrilla (2002) recomenda, ainda, que aspectos intangíveis emocionais não sejam menosprezados em projetos de ambientes comerciais, pois podem servir para reforçar o valor de compra hedonista, aportando valor agregado ao valor funcional. Essa autora sustenta que o valor hedonista é subjetivo e pessoal, e está associado com os aspectos lúdicos e os potenciais de entretenimento que uma experiência de compra pode proporcionar. $\mathrm{O}$ prazer que deriva dessa experiência é, segundo a mesma autora, um aspecto que surge como uma alternativa estratégica para compensar as opções de compra via telefone ou on-line, atualmente valorizadas pelo consumidor, graças a sua eficiência.

Entendendo o valor de compra como uma resposta interna do consumidor ao ambiente de varejo, os autores têm dividido esses valores em utilitários e hedônicos (BABIN, DARDEN e GRIFFIN, 1994). Os valores de compra utilitários emergem quando a tarefa de compra é completada com sucesso e eficiência (BABIN e BABIN, 2001). Nesse sentido, eles são provenientes de resultados relativamente tangíveis da experiência de compra, como uma aquisição eficiente de um produto (BABIN e ATTAWAY, 2000). Portanto, os valores utilitários são primariamente funcionais e racionais, e representam o quanto o "trabalho de compra" é bem-feito (BABIN, GONZALES e WATTS, 2007). Já os valores de compra hedônicos são resultado de uma gratificação pessoal imediata derivada do entretenimento e de benefícios emocionais e sociais resultantes das atividades de compra (BABIN e BABIN, 2001), entre os quais a recreação, a imersão e a alegria na experiência de compra (BABIN e ATTAWAY, 2000), sendo primariamente afetivos (BABIN, GONZALES e WATTS, 2007).

Como decorrência, Babin e Attaway (2000) postulam que os pesquisadores reconhecem que o valor da compra engloba mais do que simplesmente uma utilidade funcional. A compra pode ser valorizada a partir de uma pers- 
pectiva orientada para a tarefa na qual os consumidores encontram um item que procuram, recebem um serviço pretendido ou adquirem uma informação útil, englobando aspectos mais tangíveis. Porém, a compra também pode gerar valor a partir de uma experiência na forma de gratificação pessoal, englobando assim aspectos mais intangíveis e emocionais. Portanto, os valores chamados utilitários são mais orientados à tarefa, e os valores hedônicos, mais orientados pela experiência de compra em si.

Buscando um resgate dos estudos anteriormente apresentados, observa-se que os clientes percebem na experiência de compra valores utilitários e hedônicos, e que os autores utilizam conceitos complementares e nomenclaturas diversas para caracterizar as evidências decorrentes do ambiente de prestação de serviço do varejo. O "ambiente global" de um ponto de venda referido por Zorrilla (2002), mencionado como "atmosfera", por Gatto (2002) e como "evidência física" nos "cenários de serviços" por Zeithman e Bitner (2003), pode ser, de maneira mais ampla, definido como "o ambiente onde o serviço é executado e onde a empresa interage com o cliente, ou seja, qualquer componente tangível que facilite o desempenho ou a comunicação do serviço" (ZEITHMAN e BITNER, 2003, p. 232). A evidência física dos "cenários de serviços" e seus impactos na percepção e comportamento do consumidor aparecem sob diversas abordagens na literatura de marketing de serviços e de design. O fato é que os clientes têm dificuldade para compreender o conceito dos serviços e até mesmo de certos produtos, dada sua intangibilidade. Diante dessa dificuldade, os consumidores tentam reduzir suas incertezas procurando "sinais" da qualidade do serviço a partir de indicativos tangíveis, ou evidências físicas dos equipamentos utilizados, das pessoas envolvidas e das comunicações que recebem (LOVELOCK e WRIGHT, 2001; ZEITHAML e BITNER, 2003).

Para Lovelock e Wright (2001), a evidência física é um dos oito componentes da administração integrada do serviço, e diz respeito aos objetos tangíveis encontrados pelos clientes no ambiente de sua realização, bem como às metáforas tangíveis utilizadas em comunicações como propaganda, símbolos e marcas registradas. Entre os exemplos de elementos genéricos das evidências físicas estão todos os aspectos das instalações físicas da organização. A aparência de edifícios, jardins, veículos, mobília interior, equipamentos, membros do quadro de pessoal, placas, material impresso e outras indicações visíveis fornece evidências tangíveis da qualidade do serviço de uma organização (LOVELOCK e WRIGHT, 2001).

Já Zurlo (2003) traz à tona o conceito de Sistema Produto-Serviço (SPS), que, segundo esse autor, é um con- junto harmônico e coerente de produto, serviço, comunicação e outros elementos que registram os momentos de contato entre a empresa e seu consumidor: da logomarca ao ponto de venda, da publicidade ao comportamento dos funcionários em contato com os clientes. Sob a ótica do marketing tradicional, a noção de SPS surge a partir da evolução da ideia do produto per se, para uma entidade material com inseparáveis componentes intangíveis, ou seja, um sistema de serviços dentro do qual o produto é usado. Sob a ótica do marketing de serviços, um SPS é a evolução de um serviço tradicional, standard e genérico, em direção a um serviço personalizado (ex: Internet Banking) (MORELLI, 2002). O modelo conceitual de um SPS, encontrado também nos estudos de Mont e Plepys (2003), demonstra que os consumidores de um SPS estão expostos tanto à dimensão do produto quanto à do serviço. Esses consumidores, além disso, contam com os elementos tangíveis das dimensões infraestrutura e network, que apoiam a entrega do SPS.

A combinação dos estímulos, ou evidências físicas, presentes na atmosfera de um estabelecimento induz diferentes emoções, fazendo com que os consumidores tenham diferentes experiências de compra (ZEITHAML e BITNER, 2003). Nesse sentido, Schimitt (2000) argumenta que a experiência é a ampliação da oferta de bens e serviços que pode ser atingida por meio do uso estratégico de estímulos sensoriais que influenciam emotivamente os clientes e a equipe de vendas.

Essa experiência emocional do cliente no ambiente de compra deve ser entendida como uma estratégia para agregar valor ao cliente, na qual entretenimento e criatividade são apenas alguns dos ingredientes utilizados. Para tanto, a empresa deve, em primeiro lugar, perceber as "pistas", ou seja, as indicações de como será a experiência que oferece a seus clientes (BERRY e outros, 2003). Além da concepção de "pistas", a literatura aborda, nesse contexto, outros conceitos, tais como os "provedores-chave de experiência" de Schimitt (2000) e "palco" de Pine II e Gilmore (1998).

Diante desse rol de estudos, percebe-se na literatura uma preocupação recorrente em articular metodologicamente a instrumentação e a gestão dos componentes de um ambiente de serviço, a fim de favorecer os seus usuários em aspectos cognitivos e emocionais. O Quadro 1 apresenta uma síntese dos principais estudos sobre o tema, referindo os respectivos autores, as dimensões propostas nesses estudos e os elementos tangíveis componentes das dimensões.

A seguir são descritos os procedimentos metodológicos utilizados neste estudo. 


\section{MÉTODO}

O método utilizado para estimar o impacto de fatores visuais de design sobre a percepção de valor, por parte dos clientes, de um ponto de venda com autosserviço foi a avaliação das relações estruturais propostas entre as variáveis latentes (Hair e outros, 1998), por meio da aplicação de modelagem de equações estruturais (Hoyle, 1995), utilizando-se a estratégia de modelagem confirmatória (HAIR e outros, 1998; HOYLE, 1995). Para tanto, foram considerados os dados coletados em um cross-sectional survey (MALHOTRA, 2001), realizado com estudantes de universidades brasileiras, tendo como referência três livrarias com autoatendimento, ilustradas por fotos.
O estudo, desenvolvido em duas etapas, envolveu uma fase quantitativa, com a aplicação de questionário estruturado, precedida por uma etapa qualitativa, que identificou os principais fatores visuais de design de lojas de varejo de autosserviço, bem como valores utilitários e hedônicos na percepção dos clientes desse setor. A partir das descobertas da análise dos dados qualitativos e da sua devida contraposição com os fundamentos teóricos sobre o tema, foi possível a formulação de hipóteses relativas ao impacto dos fatores visuais de design sobre o valor de compra percebido pelo cliente, compondo o modelo estrutural testado na etapa quantitativa.

Os detalhes dos procedimentos metodológicos utilizados na realização das duas etapas desta pesquisa são apresentados a seguir.

Quadro 1 - Síntese dos estudos sobre evidência física

\section{AUTOR (ES)}

Bitner (1992)

Sherman e outros (1997)

Baker e outros (2002)

Gatto (2002)

Zorrilla (2002)

Berry e outros (2003)

Schimitt B. (2000)

Pine II e Gilmore (1998)

Zurlo (2003);

Morelli (2002);

Mont e Plepys

(2003)

Lovelock e Writght

(2001)

\section{DIMENSÕES}

Evidência física em três dimensões: ambiente; espaço-função; sinalização, símbolos e objetos.

Evidências de design do ambiente como: organização, dimensão dos espaços de circulação, limpeza e exposição das mercadorias.

Fatores sociais, ambientais e de design.

Evidências da atmosfera do ponto de venda: fatores táteis, sonoros, gustativos, olfativos, visíveis e sociais.

Baseia-se nas dimensões ambientais de Bitner (1992), acrescentando a dimensão exterior.

Pistas - fragmentos de informação ou provas físicas divididas em duas categorias: pistas funcionais (mecânicas) e emocionais (humanas).

Dimensões relacionadas aos provedores de experiência.

Pistas de um tema preestabelecido para a experiência de consumo como um "evento memorável".

Conjunto de elementos integrados, harmônicos e coerentes de produto, serviço, comunicação etc.

Composto das Comunicações de Marketing.

\section{ELEMENTOS TANGIVEIS}

Fatores Visuais de Design / Interno: sinais e símbolos, leiaute, merchandising (disposição da mercadoria), equipamentos, displays, uniformes, móveis, estilo, decoração, arquitetura interna.

Fatores Visuais de Design / Externo: logo, vitrine, entrada, fachada.

Fatores Ambientais Visiveis: materiais utilizados, cores, luzes.

Fatores Ambientais Percebiveis: temperatura, sons, cheiros, sabores.

Fatores Sociais: interações entre clientes e funcionários, densidade de clientes.

Pistas mecânicas, emitidas por objetos (cheiros, sons, visões, sabores e textura do produto ou serviço comercializado).e ambiente (leiaute) onde a experiência se dá.

Comunicações, mídia eletrônica, co-marcas, espaços ambientais, sinais e símbolos, presença do produto e pessoas.

Evidências do tema - Nome, do local, mix de lembranças, uso de sinais que harmonizem sensações positivas, uso dos cinco sentidos.

Logomarca, ponto de venda, ambiente, sinais e símbolos, leiaute, publicidade,

Displays do varejo, simbologia, decoração interna, equipamentos, uniformes, feiras e exposições. 


\section{Etapa qualitativa}

O método aplicado exigiu a elaboração de instrumentos de coleta para a mensuração dos construtos envolvidos na pesquisa, ou seja, a identificação dos indicadores de mensuração dos fatores visuais de design e dos valores percebidos pelo consumidor no varejo de autosserviço. Para tanto, foram realizadas entrevistas em profundidade, organizou-se um grupo de foco e aplicou-se a técnica projetiva de "resposta por imagem" (MALHOTRA, 2001). Os dados qualitativos foram analisados mediante a técnica de análise de conteúdo (BARDIN, 1977), com a abordagem temática ou categorial. Os resultados foram analisados em função das ideias ou palavras que continham (enunciados), sendo estas determinadas a partir do referencial teórico e diretamente relacionadas às dimensões pesquisadas. O conteúdo foi ordenado e integrado em função dos objetivos perseguidos. Os resultados encontrados foram comparados entre si, buscando-se as convergências e discrepâncias entre eles. Esses procedimentos foram complementados pela revisão da literatura.

As entrevistas em profundidade foram realizadas com sete profissionais especializados na elaboração de projetos para ambientes comerciais, partindo-se de roteiro estabelecido com base na revisão da literatura. Os profissionais foram escolhidos por julgamento, entre os associados da Associação de Profissionais em Design do Rio Grande do Sul (APDesign) e da Associação de Arquitetos de Interiores do Rio Grande do Sul (AAI), seguindo-se os seguintes critérios: profissionais com formação superior em Arquitetura ou Design com experiência superior a cinco anos no projeto para ambientes de autosserviço ou arquitetura comercial em geral.

O grupo de foco foi organizado com oito jovens, quatro rapazes e quatro moças, de idade entre 19 e 27 anos, com perfil semelhante ao previsto para a fase descritiva, ou seja, estudantes universitários, clientes de varejo de autosserviço. Nesse grupo, depois de esclarecido o conceito de autosserviço e evidenciados os exemplos de varejo com esse tipo de atendimento, os participantes foram estimulados a referir livremente, mediante um brainstorming, aspectos que refletissem, no seu imaginário, um varejo de autosserviço ideal. Em seguida, os participantes do grupo de foco foram estimulados a referir livremente suas percepções a partir de dezoito fotos de diferentes varejos com autosserviço, escolhendo os melhores "cenários" e justificando suas escolhas.

Com o intuito de ratificar as conclusões alcançadas a partir dos dados obtidos com o grupo de foco e as entrevistas em profundidade, aplicou-se a técnica projetiva de "resposta por imagem" a um grupo de dezenove estudantes universitários, reunidos em sala de aula. Solicitou-se aos membros desse grupo que, individualmente, escrevessem as suas percepções relacionadas a aspectos de três ambientes apresentados por meio de um projetor na forma de fotos, quais sejam: aquela mais criticada na avaliação do grupo de foco (Loja 1); uma livraria com um projeto de interiores com características recomendadas pelos por profissionais do setor (Loja 2); e a livraria eleita a melhor pelo grupo de foco (Loja 3). A análise dessas percepções ratificou os resultados obtidos com as entrevistas em profundidade e o grupo de foco.

\section{Etapa quantitativa}

A partir dos resultados da etapa qualitativa, elaborouse um questionário para permitir a mensuração da intensidade dos fatores visuais de design e de valores percebidos pelos clientes nos três pontos de venda com autosserviço propostos. O instrumento de coleta se compunha de cinco blocos: um bloco inicial com informações pertinentes ao perfil da amostra; um segundo bloco para a avaliação da importância absoluta de cada um dos fatores visuais de design (Quadro 2); e três blocos consecutivos para a avaliação relativa dos fatores visuais de design e dos valores percebidos (Quadro 2) em três lojas distintas a partir das três fotos selecionadas, conforme supra referido.

Com a finalidade de obter uma maior confiabilidade das respostas conseguidas, o questionário contou também com uma pergunta filtro que inquiria com que frequência o respondente visitava livrarias. Isso possibilitou eliminar da amostra os respondentes que admitiram não frequentar esse tipo de varejo. Seguindo linha de estudos semelhantes, como o de Wolff (2002) e Tramotin (2000), optouse pela mensuração dos indicadores de fatores visuais de design e de valores percebidos pelos consumidores em varejo de autosserviço mediante perguntas estruturadas e a escala intervalar de sete pontos.

O questionário resultante desta etapa foi submetido à avaliação de dois especialistas, um da área de pesquisa, que sugeriu mudanças na ordem das perguntas, e outro da área de comunicação visual, que sugeriu a presença de pessoas em todas as fotos que retravam os ambientes submetidos à apreciação dos respondentes.

Atendidas as sugestões supracitadas, o questionário foi previamente testado em um grupo de dezessete acadêmicos de um curso de graduação de Design de Interiores. $\mathrm{Na}$ ocasião foram testadas duas formas distintas para a apresentação das imagens, ou seja, impressas ou projetadas. $\mathrm{O}$ grupo reforçou a decisão de imprimir as fotos e apresentálas junto a cada questionário, e não manifestou nenhuma dificuldade quanto ao seu preenchimento. $\mathrm{O}$ instrumento 
de coleta de dados elaborado foi então aplicado, em sala de aula, a 325 estudantes de cursos de graduação de quatro instituições de ensino superior das cidades de Porto Alegre, Canoas e Caxias do Sul.

Do total de 325 respondentes, a amostra efetivamente utilizada para as análises dos dados foi composta por 274 indivíduos, formada apenas pelos questionários considerados válidos, após a eliminação de outliers pela observação das distâncias de Mahalanobis (Hoyle, 1995), de casos com excesso de missing values, além da limitação imposta pela pergunta filtro de frequência em livrarias, no caso ao menos semestralmente.

Cabe salientar que em cada questionário estavam incluídas as percepções dos clientes quanto às três livrarias propostas como modelo para avaliação, além da avaliação da importância absoluta de cada um dos fatores visuais de design. Nesse sentido, buscando a adequação da ava- liação oferecida pelos clientes a cada uma das três lojas, seguindo sugestão oferecida por Rossi e Slongo (1997), ponderou-se cada um dos fatores visuais de design com a sua respectiva importância, por meio da operação de multiplicação das duas variáveis, para cada uma das lojas, em cada um dos questionários considerados da amostra.

\section{ANÁLISE E DISCUSSÃO DOS RESULTADOS}

Conforme sinalizado no método, a apreciação das relações existentes entre os fatores visuais de design e percepção de valor de compra de clientes de varejo de autosserviço foi avaliada pela estratégia de modelagem confirmatória. Essa avaliação foi precedida de uma etapa qualitativa que identificou os indicadores dos construtos envolvidos na pesquisa, permitindo a formulação de hipóteses de impac-

\section{Quadro 2 - Escalas utilizadas}

\section{IMPORTÂNCIA DOS FATORES VISUAIS DE DESIGN}

Marque de 1 a 7 (1 = Nada importante a 7 = Muito importante) 0 grau de importância que você atribui para as características de uma livraria listadas abaixo:

Sinalização que facilite a localização dos produtos à venda.

Corredores amplos.

Corredores sem obstáculos para a circulação.

Ambiente organizado.

Limpeza.

lluminação.

Exposição da mercadoria de modo a facilitar o manuseio.

\section{PERCEPÇÃO EM RELAÇÃO A CADA UMA DAS TRÊS LOJAS APRESENTADAS NAS FOTOS}

Marque de 1 a 7 grau de concordância/discordância (1 = Discordo totalmente e 7 = Concordo plenamente) em relação ao que você percebe por meio das fotos em anexo, na Livraria $\mathrm{X}$ :

(Fatores visuais de design)

Encontraria o que eventualmente procuro, com facilidade.

Os corredores são amplos.

Os corredores não apresentam obstáculos à circulação.

0 ambiente está organizado.

0 ambiente parece limpo.

A iluminação é adequada.

A exposição das mercadorias favorece 0 manuseio.

\section{(Valores)}

Sentir-me-ia no controle da situação para fazer minha compra.

Teria vontade de procurar uma mercadoria que desejasse.

Teria uma experiência de compra prazerosa.

0 processo de compra seria rápido.

Eu escolheria a Livraria $\mathrm{X}$ para fazer a compra de um livro. 
to dos fatores visuais de design na percepção de valor de compra por parte dos clientes, conforme descrito a seguir.

\section{Resultados da fase qualitativa}

A partir da análise de conteúdo dos resultados obtidos das entrevistas em profundidade, do grupo de foco e da técnica projetiva ("resposta por imagem"), os dados foram divididos nas duas categorias de foco do estudo, quais sejam: valores de compra em termos utilitários e hedônicos, seguindo as propostas de Babin e outros (1994) e Zorrilla, (2002); e características dos fatores visuais de design, respeitando as definições de Sherman e outros (1997), Baker e outros (2002) e Zeithaml e Bitner (2003), tendo sido os fatores visuais fortemente relatados e referidos como geradores ou antecedentes do valores de compra dos consumidores avaliados.

Seguindo as definições de Babin e outros (1994), tendo como foco os valores de compra para um consumidor de varejo de autosserviço, os resultados obtidos nas entrevistas em profundidade, no grupo de foco e na técnica projetiva - "resposta por imagem" - foram analisados sob as perspectivas funcional e hedônica.

Inicialmente, sob o ponto de vista de valores utilitários, a avaliação de algumas citações destacadas do conjunto de dados colhidos sugere que o consumidor de autosserviço prefere sentir-se livre e no controle da situação durante a tarefa de compra, ou seja, não ter que pedir ajuda para completar sua tarefa de compra.

De forma complementar, de acordo com as opiniões manifestas pelos entrevistados, os consumidores parecem não querer despender muito tempo para completar a sua tarefa de compra, buscando um processo de compra rápido.

Por outro lado, expressões de encantamento, puro divertimento, excitação e espontaneidade, que segundo Babin e outros (1994) traduzem os valores hedônicos, surgem nos depoimentos dos entrevistados em referência a ambientes onde há sofás, vegetação, iluminação natural e uso de cores. A análise dos depoimentos dos consumidores expressou a sua vontade de procurar a mercadoria desejada, além de sugerir tanto o anseio por uma experiência de compra prazerosa quanto a aspiração de se sentir à vontade, como se estivesse em casa, demonstrando uma identidade ou familiaridade com um dado ambiente de varejo de autosserviço.

Na concepção teórica de Russell e Mehrabian (1976), "prazer" refere-se à medida pela qual a pessoa se sente bem, feliz ou satisfeita na interação com um ambiente. Segundo esses autores, o prazer (ou desprazer) é um dos estados emocionais que reflete o comportamento de apro- ximação ou afastamento das pessoas, em particular dos consumidores, de um determinado local. Esse comportamento relaciona-se ao desejo de permanecer no ambiente, explorar o meio, movimentar-se no cenário, retornar outras vezes ao lugar ou, ao contrário, ir embora e não voltar por sentir ansiedade ou nervosismo por estar ali.

Além do prazer, para Russell e Mehrabian (1976), a excitação é outro estado de reação emocional que pode mediar o comportamento de aproximação ou afastamento dos consumidores em relação a um lugar. Esse estado emocional trata do grau em que a pessoa se sente alerta, estimulada ou ativa no ambiente. Nesse sentido, os participantes do grupo de foco manifestam não se sentir à vontade em ambientes onde se percebem características que inibem ou constrangem a tarefa de compra.

Ocorreram, ainda, manifestações de consumidores que se sentiram totalmente à vontade em um ambiente. Nessa linha, o anseio de sentir-se "como se estivesse em casa" sugere que um ponto de venda deva ter características que sejam familiares ao consumidor. Essa percepção de familiaridade é determinante para a escolha de um ponto de venda pelo consumidor, segundo as recomendações dos arquitetos entrevistados.

Vale ressaltar ainda que, para Babin e outros (1994), uma experiência de compra pode agregar valor tanto pela plena satisfação dos objetivos previstos com essa compra como pelo prazer que ela possa proporcionar ao consumidor. Com esses pressupostos, o valor provém da experiência de compra como um todo e não simplesmente pela aquisição de um produto. Para Zorrilla (2002), o valor de compra é uma resposta interna do consumidor ao ambiente global de um varejo onde é realizada uma experiência de compra. Assim, Babin e outros (1994) afirmam que essa experiência pode evocar tanto valores utilitários quanto valores hedônicos, destacando a subjetividade deles em virtude das questões emocionais envolvidas, além da dificuldade de tratá-los separada ou isoladamente.

Quanto às características dos fatores visuais de design, os depoimentos foram agrupados segundo o conceito de fatores de design de Baker e outros (2002) e os itens da dimensão física do ambiente propostos por Zeithaml e Bitner (2003), destacando-se os itens leiaute, iluminação e sinalização. A Tabela 1 apresenta o número de menções feitas pelo grupo de foco e durante a técnica projetiva, em que os participantes manifestaram livremente suas percepções a partir de imagens de varejos de autosserviço.

O leiaute do espaço físico, segundo Zeithaml e Bitner (2003), diz respeito à disposição dos móveis e equipamentos, à forma e ao tamanho destes itens e às relações espaciais entre eles. Esse fator visual de design foi des- 
tacado pelos arquitetos e designers entrevistados como uma importante estratégia para o estímulo à compra por impulso e à atratividade do espaço como um todo. $\mathrm{Na}$ mesma linha, o leiaute foi o fator visual de design com o maior número de menções feitas tanto pelos participantes do grupo de foco quanto pelos respondentes da técnica projetiva. Essas menções foram agrupadas, segundo classificação de Sherman e outros (1997) para as características de leiaute, em: organização do ambiente, dimensão dos corredores, circulação sem obstáculos, exposição das mercadorias e limpeza do ambiente.

Durante a sondagem com clientes de autosserviço, com base em imagens de ambientes de varejo apresentadas, constatou-se que a percepção da falta de organização do espaço físico provoca manifestações de extremo desconforto. Dos depoimentos, depreende-se que a percepção de desordem pode afetar negativamente as emoções do consumidor. Isso sugere que um ambiente de ponto de venda organizado seja um padrão esperado pelo consumidor de autosserviço. Por outro lado, a interpretação dos resultados sugere que a limpeza, assim como a organização, é uma característica desejada para o ambiente comercial de varejo. Os participantes do grupo de foco manifestaram, ainda, a importância de corredores (dimensão dos corredores) amplos para que se possa transitar livremente sem enfrentar nenhum tipo de obstáculo (circulação sem obstáculos) no processo de compra. Em relação ao leiaute, por fim, os arquitetos salientaram a influência da exposição dos produtos em prateleiras na satisfação do cliente, no sentido de facilitar o manuseio.

Nesse sentido, seguindo as proposições de Sherman e outros (1997), solidificadas pelos resultados da fase qualitativa, quanto ao leiaute, sugere-se que:

$\mathrm{H}_{\mathrm{la}}$ - o nível de organização do espaço físico afeta positivamente a percepção do valor de compra por parte do cliente. $\mathrm{H}_{\mathrm{lb}}$ - a limpeza do ambiente afeta positivamente a percepção do valor de compra por parte do cliente.

$\mathrm{H}_{1 \mathrm{c}}$ - a dimensão dos corredores afeta positivamente a percepção do valor de compra por parte do cliente.
$\mathrm{H}_{\mathrm{ld}}$ - a possibilidade de circulação sem obstáculos afeta positivamente a percepção do valor de compra por parte do cliente. $\mathrm{H}_{1 \mathrm{e}}$ - a adequada exposição das mercadorias afeta positivamente a percepção do valor de compra por parte do cliente.

Por outro lado, na sondagem com os especialistas em projeto de interiores para ambientes comerciais, a iluminação foi mencionada como um fator visual de design e que pode ter a função de estabelecer o posicionamento do empreendimento. Para os especialistas, "a iluminação faz a parte cênica do local", sendo que "uma iluminação malfeita pode comprometer". O consenso entre os entrevistados pode ser sintetizado pela seguinte declaração: "A iluminação seria um dos fatores que modifica, certamente, a percepção do consumidor".

Cabe salientar que a consideração da iluminação como um fator visual de design contradiz a posição de Baker e outros (2002) e também a de Zeithaml e Bitner (2003), para os quais a iluminação é interpretada como um fator ambiental ou condição do ambiente. No entanto, o número expressivo de menções a respeito da iluminação (ver Tabela 1) como um componente visível de design sugere que esse fator possa ser considerado também como um fator visual de design. Assim, considera-se que:

$\mathrm{H}_{2}$ - a adequação da iluminação afeta positivamente a percepção de valor de compra por parte do cliente.

A análise das entrevistas em profundidade com arquitetos e designers, tendo como referência a teoria de Zeithaml e Bitner (2003), demonstrou, ainda, a adequação de fatores visuais de design, tais como cor, imagens e materiais, dentro do contexto da sinalização. Segundo Zeithaml e Bitner (2003), muitos itens do ambiente físico servem como sinais explícitos ou implícitos da comunicação de um "cenário de serviços", facilitando o processo de localização das mercadorias. Essas autoras citam materiais e cores usadas na construção, assim como imagens, placas e objetos em geral expostos no ambiente, como sendo itens que têm as funções de criar uma impressão estética gené-

\section{Tabela 1 - Menções sobre fatores visuais de design}

\begin{tabular}{|l|c|c|}
\hline \multicolumn{1}{c|}{ FATORES VISUAIS DE DESIGN } & \multicolumn{2}{c|}{ MENÇÕES } \\
\cline { 2 - 3 } & GRUPO DE FOCO & TÉCNICA PROJETIVA \\
\hline Leiaute & 19 & 46 \\
\hline Iluminação & 14 & 29 \\
\hline Sinalização (Cor / Materiais) & 15 & 2 \\
\hline
\end{tabular}

Fonte: Coleta de dados. 
rica e de agregar significado ao ambiente. Dessa forma,

$\mathrm{H}_{3}$ - a adequação da sinalização afeta positivamente a percepção de valor de compra por parte do cliente.

As hipóteses supracitadas formaram o modelo estrutural considerado para a avaliação do impacto dos fatores visuais de design sobre a percepção de valor de compra por parte do cliente, cujos detalhes são apresentados a seguir.

\section{Avaliação quantitativa do impacto dos fatores visuais de design}

Inicialmente, na etapa quantitativa, verificou-se a percepção dos respondentes quanto aos fatores visuais de design. A Tabela 2 apresenta as médias obtidas para cada fator visual de design. Note-se que as médias identificadas para o conjunto de fatores em relação às lojas propostas no questionário corroboraram os resultados obtidos na fase qualitativa, ou seja, a Loja 1 como sendo a mais criticada, a Loja 3 eleita a melhor e a Loja 2 com uma situação intermediária.

Já a avaliação das relações de impacto dos fatores visuais de design sobre a percepção do valor de compra por parte do cliente, respeitando as hipóteses formuladas para o estudo, seguiu os passos recomendados por Hair e outros. (1998), utilizando-se o software estatístico AMOS ${ }^{\circledR}$. O modelo estrutural analisado envolveu o conjunto de valores utilitários e hedônicos percebidos pelo consumidor no varejo com autosserviço como sendo um construto de primeira ordem (BAGOZZI e EDWARDS, 1998), formado pelos cinco indicadores identificados na etapa qualitativa, considerando-o como uma resposta interna do consumidor ao ambiente do varejo (ZORRILLA, 2002), de forma agregada (BABIN e outros, 1994).

Por outro lado, no que tange à integração dos fatores visuais de design, ressalta-se que a opinião dos arquitetos e designers entrevistados corrobora a posição de Zeithaml e Bitner (2003) sobre o assunto. Tais autoras defendem que os fatores visuais de design são percebidos em conjunto pelos clientes e funcionários de um "cenário de serviços", como um padrão integrado de estímulos. Nesse sentido, com o intuito de avaliar o impacto individual de cada fator visual de design, o modelo estrutural incorporou os fatores visuais como variáveis observáveis com impacto direto sobre o construto de primeira ordem supracitado, tendo sido inseridas covariâncias entre todos os fatores visuais. A Figura 1 apresenta o modelo de mensuração utilizado.

Figura 1 - Modelo estrutural

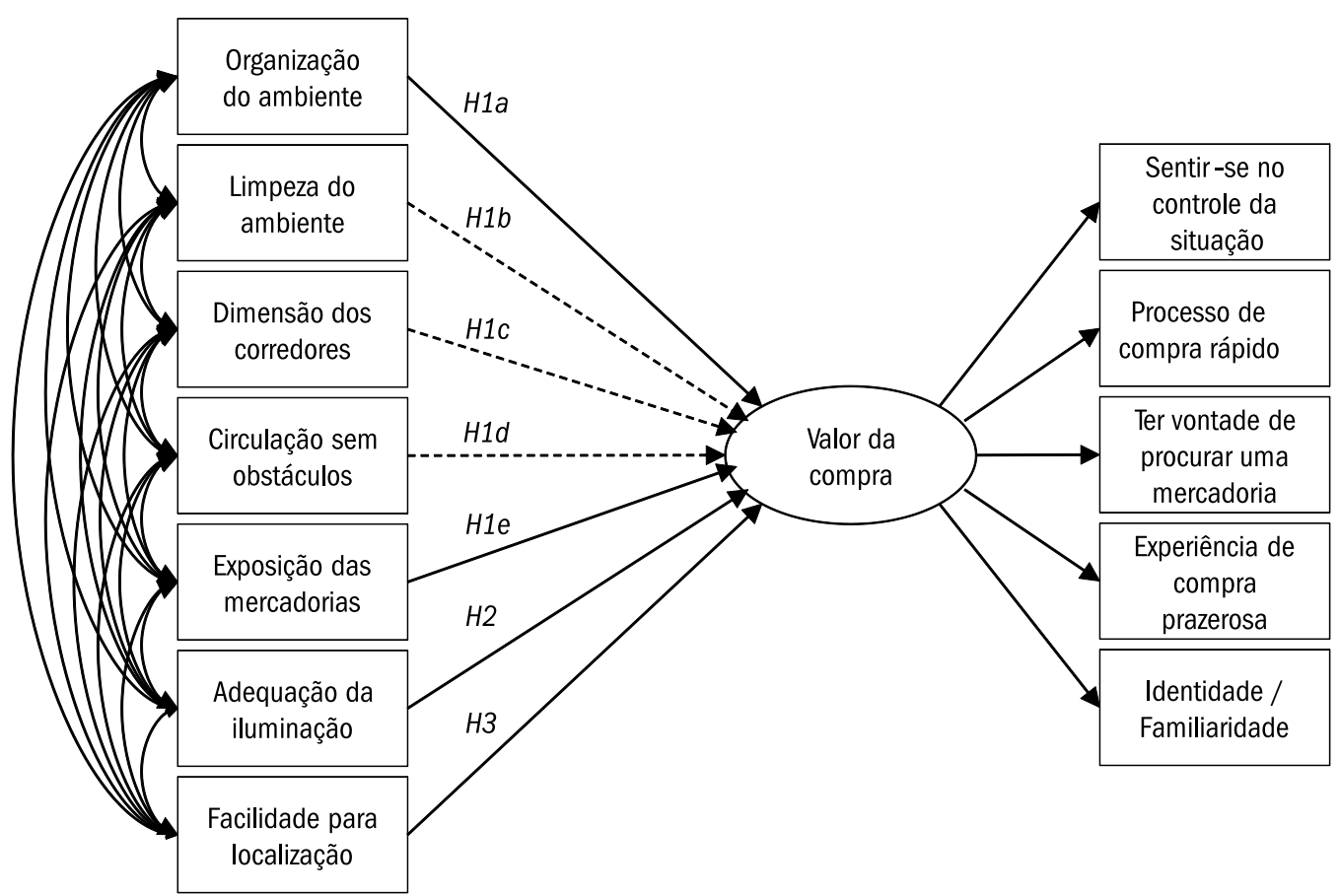

Nota: As linhas tracejadas denotam relações não significativas. 
O cálculo dos índices de ajustamento (Tabela 2) demonstrou uma boa adequação do modelo à realidade mensurada nos três conjuntos de dados testados, segundo padrões sugeridos por Hair e outros (1998). Já o exame das propriedades de unidimensionalidade, confiabilidade, validade convergente e validade discriminante demonstrou que todos os construtos envolvidos no estudo apresentaram validade de construto, seguindo recomendações de Garver e Mentzer (1999).

O exame da significância e magnitude dos parâmetros estimados (cargas fatoriais padronizadas), apresentados na Tabela 3, permitiu a verificação das hipóteses formuladas quanto ao impacto dos fatores visuais de design sobre a percepção do valor por parte dos clientes de um ponto de venda com autosserviço, uma vez confirmado o seu ajustamento, consideradas as três situações propostas (lojas 1, 2 e 3).

Note-se que a influência positiva e significativa ( $\mathrm{p}<$ $0,01$ e $\mathrm{p}<0,05)$ só se confirma em quatro dos sete fatores visuais de design, suportando as hipóteses $H_{1 a}, H_{1 e}$, $\mathrm{H}_{2}$ e $\mathrm{H}_{3}$. Em outras palavras, a organização do ambiente
$\left(\mathrm{H}_{1 \mathrm{a}}\right)$, a exposição das mercadorias $\left(\mathrm{H}_{1 \mathrm{e}}\right)$, a adequação da iluminação $\left(\mathrm{H}_{2}\right)$ e a facilidade para a localização $\left(\mathrm{H}_{3}\right)$, apresentaram influência positiva na percepção do valor de compra por parte dos clientes em relação ao ambiente de compra proposto. Essa situação se fez presente nas três diferentes lojas apresentadas aos clientes, independentemente da consideração da condição da como loja ruim, mediana ou ideal. De fato, o comportamento do impacto dos fatores visuais de design sobre o valor de compra percebido pelos clientes no ponto de venda foi bastante similar nas três situações analisadas.

Por outro lado, as características de limpeza do ambiente, de dimensões dos corredores e de circulação sem obstáculos não demonstraram apresentar influência na percepção do valor de compra de clientes de uma livraria, não oferecendo suporte às hipóteses $\mathrm{H}_{1 \mathrm{~b}}, \mathrm{H}_{1 \mathrm{c}}$ e $\mathrm{H}_{1 \mathrm{~d}}$, respectivamente. Novamente, essa situação se manifestou nos três contextos sugeridos - a mais criticada, a situação intermediária e a melhor.

Cabe, ainda, ressaltar que, dentre os fatores visuais de design que apresentaram impactos positivos e significa-

Tabela 2 - Médias obtidas para cada fator visual de design

\begin{tabular}{|l|c|c|c|}
\hline \multicolumn{1}{|c|}{ FATOR VISUAL DE DESIGN } & \multicolumn{3}{|c|}{ MÉDIA } \\
\hline & LOJA 1 & LOJA 2 & LOJA 3 \\
\hline Organização do ambiente & 2,03 & 5,20 & 6,41 \\
\hline Limpeza do ambiente & 3,24 & 5,65 & 6,52 \\
\hline Dimensão dos corredores & 2,18 & 4,45 & 5,50 \\
\hline Circulação sem obstáculos & 1,54 & 4,29 & 5,45 \\
\hline A exposição das mercadorias & 2,35 & 5,15 & 5,68 \\
\hline Adequação da iluminação & 3,07 & 4,96 & 5,76 \\
\hline Facilidade de localização & 1,94 & 4,81 & 5,90 \\
\hline
\end{tabular}

Fonte: Coleta de dados.

Tabela 3 - Índices de ajustamento

\begin{tabular}{|l|l|l|l|}
\hline & MEDIDA & LOJA 2 & LOJA 3 \\
\hline$\chi^{2 / \text { GL }}$ & 1,404 & 1,997 & 1,850 \\
\hline GFI & 0,973 & 0,959 & 0,962 \\
\hline AGFI & 0,937 & 0,903 & 0,910 \\
\hline TLI & 0,978 & 0,971 & 0,958 \\
\hline CFI & 0,989 & 0,985 & 0,979 \\
\hline RMSEA & 0,038 & 0,062 & 0,057 \\
\hline
\end{tabular}

Fonte: Coleta de dados. 
tivos sobre o valor de compra percebido pelos clientes, aquele que se mostrou com maior magnitude nas três situações propostas foi propriamente a exposição de mercadorias com facilitação do manuseio dos produtos.

Em síntese, os resultados encontrados representaram bons índices de ajustamento, conforme padrões sugeridos por Hair e outros (1998), indicando que o modelo teórico testado pode ser considerado como estatisticamente válido. Além disso, considera-se que, ao guardarem similaridade na avaliação de três lojas distintas, esses resultados sugerem uma relativa fortaleza na interpretação do fenômeno.

\section{CONCLUSÕES E IMPLICAÇÕES ACADÊMICAS E GERENCIAIS}

Esta pesquisa constatou a influência dos fatores visuais de design na percepção do valor de compra em termos utilitários e hedônicos por parte de clientes de livrarias de autosserviço. Essa constatação traz implicações seja em termos gerencias como também em termos de pesquisa, abordadas a seguir.

A dinâmica do setor varejista, segundo Zorrilla (2002), está em contínua evolução, enfrentado a cada dia uma clientela mais seletiva e exigente. As análises deste estudo referem-se à importância de valores de compra nesse segmento do comércio. Esses valores não são atribuídos apenas a questões funcionais da tarefa de compra. Além de querer despender o menor tempo possível no ponto de venda e desejar pleno controle no processo de compra, sem ter que pedir ajuda, o consumidor de autosserviço manifesta o anseio de ter uma experiência de compra prazerosa. Esse valor hedônico se manifesta na vontade de sentir-se em casa, quando frequenta pontos de venda com autosserviço. Isso obriga essas empresas a buscar soluções imaginativas que permitam tornar a clientela fiel.

Assim, os varejos necessitam abordagens mais holísticas, que considerem o efeito do impacto de elementos múltiplos, que trabalham sozinhos e em conjunto, desenvolvendo a base emocional e comportamental dos consumidores (BABIN e BABIN, 2001). As estratégias de varejo podem, portanto, ser construídas ou modificadas para oferecer uma ênfase mais funcional ou afetiva, repercutindo valores de compra utilitários e hedônicos (BABIN GONZALEZ e WATTS, 2007).

Nesse sentido, além das análises já explicitadas, os resultados deste trabalho oferecem indicações úteis a quem tem a responsabilidade de gerenciar ou conceber ambientes comerciais com varejo de autosserviço.

Dentre os fatores visuais de design identificados na literatura (ZEITHAML e BITNER, 2003; BAKER e outros, 2002; ZORRILLA, 2002), sobressaíram, nas análises realizadas, aspectos referentes a leiaute, iluminação e sinalização. Eles dizem respeito à organização e exposição de mercadorias, adequação da iluminação e facilidades para a localização de produtos. Essas são as principais características levantadas para os fatores de design citados acima e são os indicativos preponderantes na percepção do valor de compra.

É importante observar que o leiaute, a iluminação e a sinalização fazem parte de um conjunto de estímulos do ambiente que, holisticamente, influenciam a percepção das pessoas, não podendo ser considerados isoladamente. Tomando-se por base as declarações da etapa qualitativa, pode-se ponderar, por exemplo, que a organização contribui nessa direção, dando a hierarquia necessária para o discernimento e interpretação do entorno, em especial na localização das mercadorias procuradas. Isso também pode

Tabela 4 - Parâmetros estimados do modelo agregado

\begin{tabular}{|c|c|c|c|c|}
\hline \multirow[t]{2}{*}{ HIPÓTESE } & \multicolumn{3}{|c|}{ IMPACTO SOBRE O VALOR } & \multirow{2}{*}{$\begin{array}{l}\text { AVALIAÇÃO DA } \\
\text { HIPÓTESE }\end{array}$} \\
\hline & LOJA 1 & LOJA 2 & LOJA 3 & \\
\hline $\mathrm{H}_{1 \mathrm{a}}$ - Organização do ambiente >> valor da compra & $0,212 * *$ & $0,157 *$ & $0,126 *$ & Suportada \\
\hline $\mathrm{H}_{1 \mathrm{~b}}$ - Limpeza do ambiente >> valor da compra & 0,024 & 0,107 & 0,015 & Não Suportada \\
\hline $\mathrm{H}_{1 \mathrm{c}}$ - Dimensão dos corredores >> valor da compra & 0,111 & 0,062 & 0,023 & Não Suportada \\
\hline $\mathrm{H}_{1 \mathrm{~d}}$ - Circulação sem obstáculos >> valor da compra & $-0,001$ & $-0,053$ & 0,057 & Não Suportada \\
\hline$H_{1 \mathrm{e}}-\mathrm{A}$ exposição das mercadorias $>>$ valor da compra & $0,368 * *$ & $0,329 * *$ & $0,424 * *$ & Suportada \\
\hline $\mathrm{H}_{2}$ - Adequação da iluminação >> valor da compra & $0,125 *$ & $0,154 *$ & $0,133 *$ & Suportada \\
\hline $\mathrm{H}_{3}$ - Facilidade de Localização >> valor da compra & $0,166 *$ & $0,262 * *$ & $0,173 * *$ & Suportada \\
\hline
\end{tabular}

Fonte: Coleta de dados.

Nota: Os dados apresentados como "Impacto sobre o valor" representam as cargas fatoriais padronizadas. $* * p<0,01 ; * p<0,05$. 
se refletir numa percepção positiva da exposição dessas mercadorias, ao criar condições para que o consumidor possa avaliá-las com facilidade.

A organização e adequação da iluminação são características que, percebidas na sinalização, na exposição das mercadorias e nos demais aspectos do leiaute do ambiente, parecem apenas relacionar-se aos valores da compra em termos utilitários. Entretanto, os relatos dos participantes do grupo de foco sugerem que o não atendimento dos valores utilitários afeta negativamente a percepção de valores hedônicos. A relação entre valores de compra em termos utilitários e hedônicos, percebida pelos resultados qualitativos deste estudo, é também discutida no estudo de Babin e outros (1994), que respalda a necessidade de um maior aprofundamento dessa relação em pesquisas futuras.

Os projetos de design de interiores para ambientes comerciais devem considerar o conhecimento pleno das expectativas dos consumidores e o posicionamento dos concorrentes. É preciso compreender como os diversos estímulos do ambiente influem no comportamento do consumidor. Essas indicações também são referidas pelos especialistas entrevistados, como pressupostos das decisões de projeto. Os arquitetos e designers entrevistados reconhecem a importância de uma avaliação da solução de projeto implantada, embora reconheçam também a dificuldade de encontrar parâmetros para tanto.

A metodologia aplicada neste trabalho pode ser um caminho para estabelecer tais parâmetros tanto para a concepção quanto para a avaliação pós-ocupacional de ambientes comerciais, onde se leve em consideração não apenas aspectos utilitários, mas também aspectos emocionais do consumidor. Entretanto, há muito para ser pesquisado, de modo a englobar todos os requisitos necessários para tal finalidade.

Assim, em termos gerencias, entende-se que o presente estudo pode auxiliar no aprendizado metodológico para a verificação dos fatores visuais de design mais impactantes na percepção do valor de compra em um ambiente de varejo de autosserviço. Ainda que os resultados do presente estudo possam servir diretamente de base para decisões quanto à definição do ambiente físico de alguns estabelecimentos de varejo, em termos práticos, cabe destacar a importância da replicação de tais procedimentos metodológicos por parte dos gestores em suas realidades específicas, buscando uma melhor adequação das características visuais de design para os seus estabelecimentos em particular.

Seguindo considerações de Okamoto (1997), ponderase que hoje não é suficiente apenas a discussão sobre o espaço euclidiano dos ambientes, de seu acabamento, mas também a existência de qualidades que venham a atrair e tocar a sensação de conforto, de acolhimento, atendendo às dimensões psicológicas do ser humano, propiciando o sentimento de prazer nos locais de atividade de sua existência, desenvolvendo o sentido afetivo ou laço de ligação prazerosa que enseje a permanência no local.

\section{Limitações da pesquisa e sugestões para estudos futuros}

Apesar do rigor do método aplicado nesta pesquisa, algumas situações vivenciadas durante o desenvolvimento do trabalho sugerem certas limitações, e a superação de cada uma delas resultará em recomendações para pesquisas futuras.

O fato de a amostra ser constituída essencialmente por estudantes é uma limitação. Apesar de amplamente utilizada e aceita em estudos de marketing, é certo que nesse tipo de amostra existem dificuldades inerentes de generalização dos resultados em função da utilização de estudantes. Seria interessante que trabalhos futuros observassem a aleatoriedade na seleção das unidades amostrais. Outra eventual limitação refere-se ao escopo geográfico da pesquisa, dado que os respondentes eram universitários do sul do país.

Pela importância e subjetividade da dimensão do valor percebido pelo cliente em pontos de venda, eventuais estudos futuros poderiam buscar entender melhor como o consumidor elabora mentalmente essa concepção de valor. Além disso, corroborando sugestão de Babin e Attaway (2000), uma questão importante a ser investigada pelos varejistas seria como a atmosfera da loja pode criar comportamentos de compra consistentes. Por fim, uma ampliação para outros tipos de varejo torna-se relevante para verificar o quanto os resultados aqui encontrados são válidos para outros ambientes.

\section{REFERÊNCIAS}

BABIN, B. J; ATTAWAY, J. S. Atmospheric affect as a tool for creating value and gaining share of customer. Journal of Business Research, v. 49, n. 2, p. 91-99, 2000.

BABIN, B. J; BABIN, L. Seeking something different? A model of schema typicality, consumer affect, purchase intentions and perceived shopping value. Journal of Business Research, v. 54, p. 89-96, 2001.

BABIN, B. J; DARDEN, W. R; GRIFFIN, M. Work and/or fun: measuring hedonic and utilitarian shopping value. Journal of Costumer Research, $\mathrm{p}$. 644, 1994 


\section{ARTIGOS - FATORES VISUAIS DE DESIGN E SUA INFLUÊNCIA NOS VALORES DE COMPRA DO CONSUMIDOR}

BABIN, B. J; GONZALEZ, C; WATTS, C. Does Santa have a great job? Gift shopping value and satisfaction. Psychology \& Marketing, v. 24, n. 10, p. 895-917, 2007.

BAGOZZI, R. P; EDWARDS, J. R. A general approach for representing constructs in organizational research. Organizational Research Methods, v. 1, n. 1, p. 45-87, 1998.

BAKER, J; PARASURAMAN, A; GREWAL, D; VOSS, G. The influence of multiple store environment cues on perceived merchandise value and patronage intentions. Journal of Marketing, v. 66, p. 120-141, 2002.

BARDIN, Laurence. Análise de conteúdo. Lisboa: Edições 70, 1977.

BATESON, J; HOFFMAN K. Marketing de serviços. Porto Alegre: Bookman, 2001

BERRY, L; CARBONE, P; HAECKEL, H. O consumidor e as experiências. HSM Management, v. 2, n. 37, p. 74-79, 2003.

BITNER, M. J. Servicescapes: the impact of physical surroundings on customers and employees. Journal of Marketing, v. 56, p. 57-71, 1992.

CARVALHO, J. L. F. S; MOTTA, P. C. Experiências em cenários temáticos de serviços. Revista de Administração de Empresas, v. 42, n. 2, p. 54-65, 2002.

CZINKOTA, M. R. e outros. Marketing: as melhores práticas. Porto Alegre, Bookman.

GARVER, M. S; MENTZER, J. T. 1999. Logistics research methods: employing structural equation modeling to test for construct validity. Journal of Business Logistics, v. 20, n. 1, p. 33-57, 2001.

GATTO, S. L'atmosfera del punto vendita quale strumento di differenziazione dell'insegna: una verifica empirica delgli effetti della variabile olfativa. In: CONGRESSO INTERNAZIONALE "LE TENDENZE DEL MARKETING", 2002, Venezia. Anais. Venezia, 2002.

KOTLER, P. Atmospherics as a marketing tool. Journal of Retailing, v. 49, n. 3, 48-64, 1973.

KOTLER, P. Administração de marketing. São Paulo: Prentice Hall do Brasil, 2000.

KOTLER, P; HAYES, T; BLOM P. Marketing de serviços profissionais. Barueri: Manole, 2002.

KRISHNAN, B; HARTLINE, D. Brandy equity: is more important in services? Journal of Marketing, v. 15, n. 5, p. 328-342, 2001.

HAIR, J; ANDERSON, R. E; TATHAM, R; BLACK, W. Multivariate Data Analysis. 5. ed. New Jersey: Prentice Hall, 1998.

HOYLE, R. H. (Ed). Structural Equation Modeling: Concepts, Issues, and Applications. London: Sage, 1995.

LIBERALI, G. N; D'ANGELO, A; ESPINOZA, F. S. A Influência da Atmosfera de Varejo sobre os Consumidores. In: ENCONTRO NACIONAL DOS PROGRAMAS DE PÓS-GRADUAÇÃO EM ADMINISTRAÇÃO, 27, 2003, Atibaia. Anais. Atibaia: ANPAD, 2003.
LOVELOCK, C; WRIGHT, L. Serviços marketing e gestão. São Paulo: Saraiva, 2001.

MALHOTRA, N. K. Pesquisa de marketing: uma orientação aplicada. Porto Alegre: Bookman, 2001.

MORELLI, N. Designing product/service systems: a methodological exploration. Design Issues, v. 18, n. 3, p. 3-17, 2002.

MONT, O; PLEPYS, A. Costumer satisfaction: review of literature and application to product-service system. Final report for The Society of Non-Traditional Technology, Tokyo, Japan. In: International Institute for Industrial Environmental Economics. Lund, Sweden, 2003. Disponível em http://www.iiiee.lu.se. Acesso em dez. 2003.

OKAMOTO, J. Percepção ambiental e comportamento. São Paulo: Ipsis, 1997

PINE II, J. P; GILMORE, J. H. Welcome to the Experience Economy Harvard Business Review, n. 4, p. 97-105, 1998.

ROSSI, C. A. V; SLONGO, L. A. Pesquisa de satisfação de clientes: o estadoda-arte e proposição de um método brasileiro. In: ENCONTRO NACIONAL DOS PROGRAMAS DE PÓS-GRADUAÇÃO EM ADMINISTRAÇÃO, 21, 1997, Rio de Janeiro. Anais. Rio de Janeiro: ANPAD, 1997.

RUSSEL, J; MEHRABIAN, A. Environmental variables in costumer research. Journal of Costumer Research, p. 62, 1976.

SHERMAN, E; MATHUR, A; SMITH, R. B. Store environment and consumer purchase behavior: mediating role of consumer emotions. Psychology \& Marketing, 1997.

SCHMITT, B. H. Marketing experimental. São Paulo: Nobel, 2000.

TRAMONTIN A. Identificação dos itens de demanda ergonômica em lojas de cosméticos de Perfume. 2000. Dissertação de Mestrado em Engenharia da Produção, Escola de Engenharia, Universidade Federal do Rio Grande do Sul, Porto Alegre, 2000.

TREVISAN, R; SAMPAIO C. H; PERIN, M. G. Estratégia de lançamento de novos produtos na indústria automobilística: o caso do Volkswagen novo Pólo. In: Congresso Latinoamericano de Estratégia, 16, 2003, Lima. Anais. Lima: SLADE, 2003

WOLFF, F. Simbolismo no comportamento do consumidor: construindo uma nova escala. In: ENCONTRO NACIONAL DOS PROGRAMAS DE PÓS-GRADUAÇÃO EM ADMINISTRAÇÃO, 26, 2002, Salvador. Anais. Salvador, ANPAD, 2002.

ZEITHAML V. A; BITNER M. J. Marketing de serviços: a empresa com foco no cliente. Porto Alegre: Bookman, 2003.

ZORRILLA, P. Nuevas tendencias en merchandising: generar experiencias para conquistar emociones y fidelizar clientes. Distribución y Consumo, sep-oct, p. 13-20, 2002.

ZURLO, F. Una introduzione sul design strategico. In: Encontro ÍtaloBrasileiro de Design, 1, 2003, Curitiba. Palestra. Curitiba, 2003. 